Check for updates

Cite this: Mater. Adv., 2021, 2, 448

Received 31st August 2020, Accepted 5th December 2020

DOI: 10.1039/d0ma00658k

rsc.li/materials-advances

\section{Chemisorption of $\mathrm{CO}_{2}$ on diaminated silica as bicarbonates and different types of carbamate ammonium ion pairs}

\author{
Anthony E. Szego, Aleksander Jaworski and Niklas Hedin (D)*
}

\begin{abstract}
The chemisorption of $\mathrm{CO}_{2}$ on aminated silica has a rich chemistry, and its details are important to research in relation to $\mathrm{CO}_{2}$ capture and catalytic chemistry. In this study, such chemisorption was investigated on aminated and diaminated silica with ${ }^{1} \mathrm{H}$ and ${ }^{13} \mathrm{C}$ solid state nuclear magnetic resonance (NMR) spectroscopy under dry and wet conditions. Fast magic-angle spinning (MAS) allowed us to obtain high resolution spectra. Porous silica was modified into a monoaminated version using (3-aminopropyl)triethoxysilane (APTS) and a diaminated one by using 3-(2-aminoethylamino)propyltriethoxysilane (AEAPTS). From the corresponding NMR spectra we could conclude that, under dry conditions, $\mathrm{CO}_{2}$ chemisorbed as carbamic acid and carbamate ammonium ion pairs and gave similar spectra for both directly-excited ${ }^{13} \mathrm{C}$ and under cross-polarization (CP) $\left\{{ }^{1} \mathrm{H}\right\}{ }^{13} \mathrm{C}$ MAS NMR. Under wet conditions, direct excitation and $\left\{{ }^{1} \mathrm{H}\right\}^{13} \mathrm{C}$ CPMAS NMR showed that carbamate ammonium ion pairs formed along with bicarbonates $\left(\mathrm{HCO}_{3}{ }^{-}\right)$. For the wet conditions, the ${ }^{13} \mathrm{C}$ and ${ }^{1} \mathrm{H}$ NMR spectra were especially well resolved, and we could detect two different types of carbamate ammonium ion pairs forming on the diaminated silica. We conclude that carbamate ammonium ion pairs and $\mathrm{HCO}_{3}{ }^{-}$moieties can be detected by $\left\{{ }^{1} \mathrm{H}\right\}^{13} \mathrm{C} M A S \mathrm{NMR}$, at least qualitatively, in addition to the more time consuming direct excitation.
\end{abstract}

\section{Introduction}

Pilot plants for the capturing of carbon dioxide $\left(\mathrm{CO}_{2}\right)$ are based on the use of established scrubbing technology with aminated solvents that allows the capturing and relatively easy release/ regeneration of the captured $\mathrm{CO}_{2} \cdot{ }^{1,2}$ There is a major issue with these practices though, which include the high energy demand for regeneration of the solvent, corrosion of equipment, and the evaporation and leaching of the amine or associated degeneration products. Immobilized amines on porous solid supports could possibly reduce the energy required for regeneration, limit the corrosion, and the evaporation of the amines. ${ }^{3-6}$

Mesoporous silica, in particular, has been very popular as a solid to immobilize amine functions and reduce corrosion and leaching. ${ }^{7-10}$ One of three ways can be used to modify silica with amines: by physical immobilization of compounds on the surface, chemical tethering, or crosslinking of polyamines throughout the pores of the silica. The amine-modified solid adsorbents - similarly to liquid amines - have been shown to exhibit a highly selective uptake of $\mathrm{CO}_{2}$ and a high capacity for $\mathrm{CO}_{2}$ uptake at low partial pressures of the $\mathrm{CO}_{2} \cdot{ }^{11-13}$

Department of Materials and Environmental Chemistry, Stockholm University, Stockholm, SE-10691, Sweden. E-mail: niklas.hedin@mmk.su.se
Despite the advantages these types of amine-modified sorbents have, full mechanistic understanding of the reaction of the amines with $\mathrm{CO}_{2}$ has yet to be achieved. ${ }^{14-20}$ It is known from previous works that in the reactions between $\mathrm{CO}_{2}$ and amines in the presence of water, three main species are involved: carbamic acid, carbamate ammonium ion pairs, and bicarbonates $\left(\mathrm{HCO}_{3}{ }^{-}\right)$. Even though the formation of $\mathrm{HCO}_{3}{ }^{-}$has been shown to enhance the so-called amine efficiency, ${ }^{21-23}$ the formation of these species could potentially be considered a drawback in the context of $\mathrm{CO}_{2}$ capture due to the expected higher energy required for the regeneration of the material, and overall reduced adsorption and desorption rates, despite the increase in sorption capacity. ${ }^{24-26}$

The existence of $\mathrm{HCO}_{3}{ }^{-}$in $\mathrm{CO}_{2}$ chemisorption reactions on moist solid amines has been questioned in the past. ${ }^{14,15,23,27-29}$ In light of findings from the liquid state amine- $\mathrm{CO}_{2}-\mathrm{H}_{2} \mathrm{O}$ chemistries, ${ }^{30-32}$ it would seem obvious that $\mathrm{HCO}_{3}{ }^{-}$should form within pores of moist amine-modified sorbents. However, it has not been easy to detect $\mathrm{HCO}_{3}{ }^{-}$by solid-state NMR and, also, its IR signatures have been difficult to assign. ${ }^{11}$ Solid-state NMR is used extensively to characterize chemisorption products in general, because it can determine the structures of non-crystalline systems. ${ }^{33,34}$ This versatility also allows the method to be used in the identification and quantification of the analyzed products, in situ and ex situ. ${ }^{14,33,35}$ In NMR, in 
particular, the ${ }^{13} \mathrm{C}$ chemical shift of $\mathrm{HCO}_{3}{ }^{-}$appears at a range of values, depending on the environment that contributes to the shielding experienced by the ${ }^{13} \mathrm{C}$ nucleus. ${ }^{36}$ As a result, its NMR resonance may be masked by that of potentially more prominent carbamate or carbamic acid resonances. For this reason, the samples presented in this paper have been divided into "wet" and "dry" samples, as the absence of $\mathrm{H}_{2} \mathrm{O}$ is known to restrict the formation of $\mathrm{HCO}_{3}{ }^{-37}$ Carbonates $\left(\mathrm{CO}_{3}{ }^{2-}\right)$ will not be observed in the present paper because conditions that favor its formation $(\mathrm{pH}>10.3)$ are not present.

Despite the aforementioned debate regarding the involvement of $\mathrm{HCO}_{3}{ }^{-}$in these types of systems, previous work done recently by Chen et $a{ }^{27}{ }^{27}$ was able to find and assign a peak to this species. They could unambiguously show with the so called direct polarization ${ }^{13} \mathrm{C}$ NMR method that $\mathrm{HCO}_{3}{ }^{-}$formed when the samples had been subjected to liquid $\mathrm{H}_{2} \mathrm{O}$. The fast dynamics and, in our interpretation, the liquid-like character of the formed $\mathrm{HCO}_{3}{ }^{-}$dissolved in the pores largely filled with $\mathrm{H}_{2} \mathrm{O}$, were the reasons why $\mathrm{HCO}_{3}{ }^{-}$was not easily detected at room temperature in that study and gave convincing insight as to why it had not earlier been detected by the more commonly used cross-polarization method, here called as $\left\{{ }^{1} \mathrm{H}\right\}{ }^{13} \mathrm{C}$ NMR. The absence of the $\left\{{ }^{1} \mathrm{H}\right\}^{13} \mathrm{C}$ NMR signal for $\mathrm{HCO}_{3}{ }^{-}$in most studies has likely been related to that the details of the cross-polarization dynamics associated to its presumed liquidstate-type character are not fully taken into account, which in turn will hinder an effective magnetization transfer. $\mathrm{H}_{2} \mathrm{O}$ adsorbs in significant amounts on amine-modified adsorbents. ${ }^{15,22}$

The work presented here is meant to further contribute to this exploration of the presence of $\mathrm{HCO}_{3}{ }^{-}$in these systems. We show that $\left\{{ }^{1} \mathrm{H}\right\}^{13} \mathrm{C}$ NMR could be used at least qualitatively to identify $\mathrm{HCO}_{3}{ }^{-}$for samples being rich in co-adsorbed $\mathrm{H}_{2} \mathrm{O}$ and that two different types of carbamates formed in moist diaminated silica on the chemisorption of $\mathrm{CO}_{2}$.

\section{Materials and synthesis}

Chromatographic particles of porous silica, Davisil LC60 (Grace Davison), was used as a porous support. It had a particle size of 40-63 $\mu \mathrm{m}$, and a surface area of $550 \mathrm{~m}^{2} \mathrm{~g}^{-1}$. The support was used as received after a drying treatment at a temperature of $110{ }^{\circ} \mathrm{C}$ for $16 \mathrm{~h}$. Analytical- grade toluene ([CAS: 108-88-3], Sigma-Aldrich $99.8 \%$ ) with $0.03 \mathrm{wt} \% \mathrm{H}_{2} \mathrm{O}$ was used. The porous silica was modified with (3-aminopropyl)triethoxysilane (APTS) ([CAS: 919-30-2], Sigma-Aldrich > 98\%) and 3-(2-aminoethylamino) propyltriethoxysilane (AEAPTS) ([CAS: 5089-72-5], Sigma-Aldrich $>96 \%$ ). Labelled ${ }^{13} \mathrm{CO}_{2}$ ([CAS: 1111-72-4], Sigma-Aldrich $99 \mathrm{~atm} \%{ }^{13} \mathrm{C}$ ) was used for the NMR experiments.

\subsection{Modifications with propylamine and a diamine groups}

The porous silica was dried at a temperature of $110{ }^{\circ} \mathrm{C}$ before synthesis, and the synthesis procedure was adapted from methods previously reported in the group. ${ }^{38}$ In summary, for each synthesis 3 grams of porous silica and $180 \mathrm{~cm}^{3}$ of toluene were added to a three-necked flask equipped with a Dean-Stark reflux condenser. The solutions were heated to $50{ }^{\circ} \mathrm{C}$ under stirring for $30 \mathrm{~min}$; a previously established amount of $\mathrm{H}_{2} \mathrm{O}$ was added and the mixtures were refluxed for a period of $1 \mathrm{~h}$. After this period had elapsed, the required amount of silane monomer was added (APTS or AEAPTS) and left to reflux for $24 \mathrm{~h}$. Finally, the solid was filtered off, washed with ethanol $\left(50 \mathrm{~cm}^{3} \times 3\right)$ and toluene $\left(50 \mathrm{~cm}^{3} \times 2\right)$ and dried overnight at a temperature of $100{ }^{\circ} \mathrm{C}$. The sample modified with the monoamine monomer is called Silica_APTS, and the one with the diamine monomer Silica_AEAPTS.

\section{Characterization}

\subsection{Solid state nuclear magnetic resonance}

In order to ensure that all chemisorbed species formed were detected, two protocols for the ${ }^{13} \mathrm{C}$ NMR and one protocol for the ${ }^{1} \mathrm{H}$ NMR were used for each sample. We studied ${ }^{1} \mathrm{H}$ and ${ }^{13} \mathrm{C}$ NMR responses using direct excitation, and $\left\{{ }^{1} \mathrm{H}\right\}{ }^{13} \mathrm{C}$ NMR using cross-polarization (CP). $99 \%{ }^{13} \mathrm{C}$-enriched $\mathrm{CO}_{2}$ was used for the experimentation. All NMR experiments were performed at the magnetic field strength of 14.1 $\mathrm{T}$ (Larmor frequencies of 600.1 and $150.9 \mathrm{MHz}$ for ${ }^{1} \mathrm{H}$ and ${ }^{13} \mathrm{C}$, respectively) with a Bruker Avance-III spectrometer.

${ }^{1} \mathrm{H}$ MAS NMR experiments were carried out with a $1.3 \mathrm{~mm}$ probehead at the MAS rate of $60.00 \mathrm{kHz}$. Acquisitions involved rotor-synchronized, double-adiabatic spin-echo sequence with a $90^{\circ}$ excitation pulse of $1.1 \mu \mathrm{s}$, followed by two $50.0 \mu \mathrm{s}$ tan h per tan high-power adiabatic pulses with $5 \mathrm{MHz}$ frequency sweep. ${ }^{39,40} 256$ signal transients with 5 s relaxation delay were collected for each sample. Rotors were filled with powderous Silica_APTS and Silica_AEAPTS and pre-treated under high dynamic vacuum (turbo pump) on the degas port of a Micrometrics ASAP2020 volumetric adsorption analyzer at a temperature of $110{ }^{\circ} \mathrm{C}$. After this degassing, the Silica_APTS and Silica_AEAPTS were divided into "dry" and "wet" samples. The dry samples were subjected to 1 bar of $\mathrm{CO}_{2}$ enriched in ${ }^{13} \mathrm{C}$, at $25{ }^{\circ} \mathrm{C}$, for a period of 48 hours, and, finally, the rotors were capped in a glovebox under a continuous flow of $\mathrm{N}_{2}$ for these dry samples. For the wet samples, the degassed rotors were conditioned in an enclosed environment, for $16 \mathrm{~h}$, where the air was saturated with $\mathrm{H}_{2} \mathrm{O}$ after which they were subjected to 1 bar of $\mathrm{CO}_{2}$ enriched in ${ }^{13} \mathrm{C}$ in a fashion similar to that of the dry samples. The rotors were rapidly capped before each measurement within the glovebox.

Direct excitation ${ }^{13} \mathrm{C}$ and $\left\{{ }^{1} \mathrm{H}\right\}{ }^{13} \mathrm{C}$ CPMAS NMR spectra were recorded with a $4 \mathrm{~mm}$ probehead and $14.00 \mathrm{kHz}$ MAS rate. ${ }^{13} \mathrm{C}$ MAS NMR spectra involved a $4.0 \mu \mathrm{s} 90^{\circ}$ excitation pulse and Spinal64 ${ }^{1} \mathrm{H}$ decoupling sequence ${ }^{41}$ operated at proton nutation power of $65 \mathrm{kHz} .128$ signal transients with $300 \mathrm{~s}$ relaxation delay were collected. For $\left\{{ }^{1} \mathrm{H}\right\}^{13} \mathrm{C}$ CPMAS acquisitions HartmannHahn matched radiofrequency fields were applied for a contact interval of $0.5 \mathrm{~ms}$ and employed the same proton decoupling scheme. 16384 signal transients with 2 s relaxation delay were collected. Chemical shifts are referenced with respect to neat tetramethylsilane (TMS). 


\section{2. $\mathrm{CO}_{2}$ adsorption measurements}

Adsorption and desorption isotherms of pure $\mathrm{CO}_{2}$ on Silica APTS and Silica_AEAPTS were measured at a temperature of $0{ }^{\circ} \mathrm{C}$ using a Micrometrics ASAP2020 volumetric adsorption analyzer. These were compared to a sample of unmodified silica that had undergone the same toluene treatment without the inclusion of silane monomer. The volumetric uptake of $\mathrm{CO}_{2}$ was measured at $\mathrm{CO}_{2}$ pressures from 0.001 to 1 bar under equilibrium conditions. Thermal control was achieved by immersing the samples in a Dewar flask filled with $\sim 3 \mathrm{dm}^{3}$ of $\mathrm{H}_{2} \mathrm{O}$ and ice, which equilibrated the temperature to $0{ }^{\circ} \mathrm{C}$. For these measurements, the samples were pretreated under high dynamic vacuum conditions at $110{ }^{\circ} \mathrm{C}$ for $10 \mathrm{~h}$ before experimentation.

\subsection{Thermogravimetric analysis}

Thermogravimetric analysis (TGA) was used to record the mass loss on heating Silica_APTS and Silica_AEAPTS using a TA Instruments Discovery (TA Instruments, Stockholm, Sweden) thermobalance in dry air, for which samples were heated from 50 to $950{ }^{\circ} \mathrm{C}$ at a rate of $10{ }^{\circ} \mathrm{C} \mathrm{min}{ }^{-1}$ in a platinum cup.

\section{Results and discussion}

\subsection{Solid-state NMR}

In order to identify the species formed after the chemisorption of $\mathrm{CO}_{2}$ on Silica_APTS and Silica_AEAPTS under "wet" and "dry" conditions, isotopic labelling in ${ }^{13} \mathrm{C}$ was used together with directly-excited ${ }^{13} \mathrm{C},\left\{{ }^{1} \mathrm{H}\right\}{ }^{13} \mathrm{C}$, and ${ }^{1} \mathrm{H}$ MAS NMR spectroscopy. Under dry conditions, carbamate ammonium ion pairs and carbamic acid groups were detected on Silica_APTS and Silica_AEAPTS, and the corresponding directly-excited ${ }^{13} \mathrm{C}$ and $\left\{{ }^{1} \mathrm{H}\right\}^{13} \mathrm{C}$ MAS NMR spectra in Fig. 1 were similar. The broad resonance at a ${ }^{13} \mathrm{C}$ chemical shift of about $165 \mathrm{ppm}$ was assigned to the carbamate part of carbamate ammonium ion pairs, ${ }^{14,42-44}$ and the broad resonance at about $160 \mathrm{ppm}$ to what seems to be carbamic acid. ${ }^{14,42,44,45}$ Under wet conditions, carbamate ammonium ion pairs and $\mathrm{HCO}_{3}{ }^{-}$species were detected in the directly excited ${ }^{13} \mathrm{C}$ and $\left\{{ }^{1} \mathrm{H}\right\}{ }^{13} \mathrm{C}$ NMR spectra in Fig. 1. The narrow ${ }^{13} \mathrm{C}$ NMR signals at chemical shits of 161.4 and $161.7 \mathrm{ppm}$ were assigned to $\mathrm{HCO}_{3}{ }^{-}$using the assignments of Chen et al. ${ }^{27}$ supported by assignments in related liquid state systems. ${ }^{46}$ The relative signal intensities for $\mathrm{HCO}_{3}{ }^{-}$in Fig. 1 were much smaller for the $\left\{{ }^{1} \mathrm{H}\right\}{ }^{13} \mathrm{C}$ NMR spectra as compared to those observed in the directly excited ${ }^{13} \mathrm{C}$ NMR spectra for both Silica_APTS and Silica_AEAPTS, which is in line with the general findings of the study by Chen et $a .^{27}$ about a reduced or vanishing cross-polarization efficiency for these $\mathrm{HCO}_{3}{ }^{-}$. We ascribe that we, in contrast to Chen et al., were able to clearly detect the $\mathrm{HCO}_{3}{ }^{-}$, also at room temperature, either to the delicate details in the cross-polarization conditions or that we had equilibrated the samples with gaseous $\mathrm{H}_{2} \mathrm{O}$ (at 100\% relative humidity). Note that the relative ${ }^{13} \mathrm{C}$ NMR signal intensity for the $\mathrm{HCO}_{3}{ }^{-}$in the directly excited ${ }^{13} \mathrm{C}$ NMR spectra

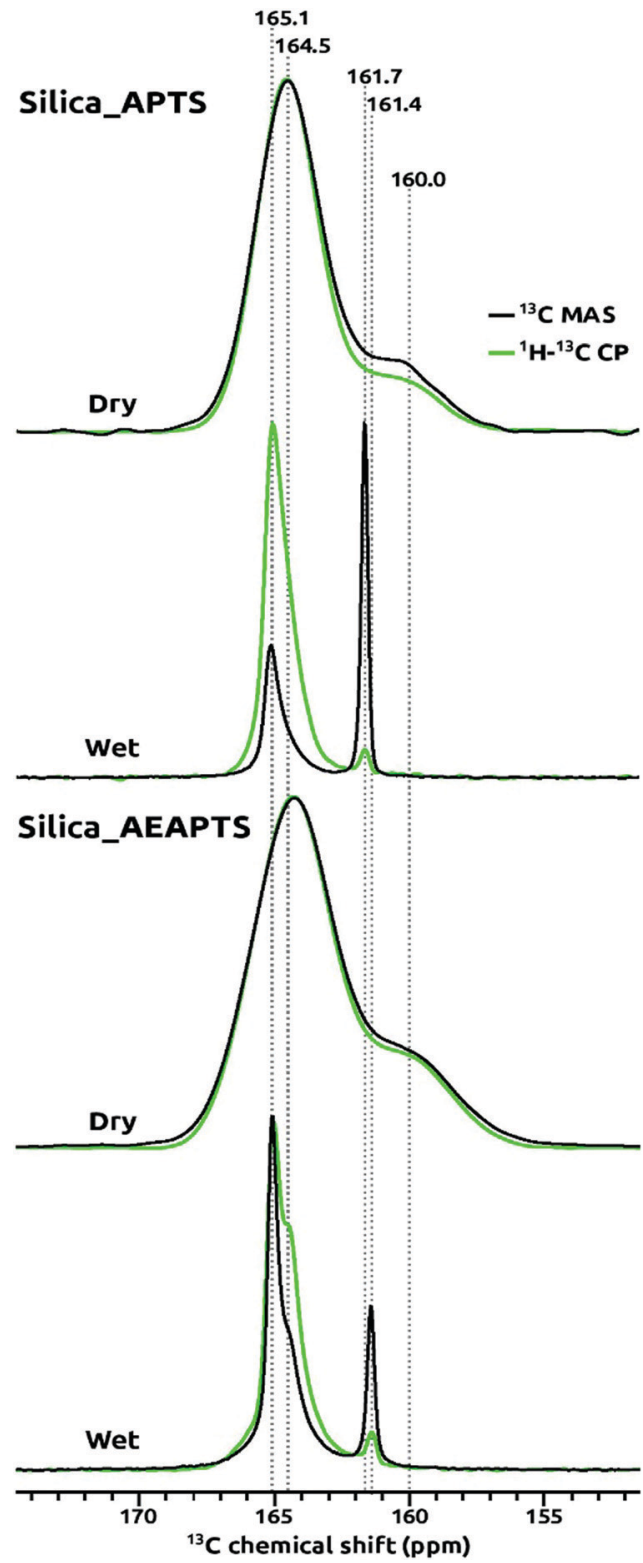

Fig. $1{ }^{13} \mathrm{C}$ solid-state NMR spectra recorded in wet and dry conditions for samples modified with (3-aminopropyl)triethoxysilane (Silica_APTS) and 3-(2-aminoethylamino)propyltriethoxysilane (Silica_AEAPTS). Black lines correspond to direct excitation ${ }^{13} \mathrm{C}$ NMR and the green ones to crosspolarization $\left(\left\{{ }^{1} \mathrm{H}\right\}^{13} \mathrm{C}\right) \mathrm{NMR}$. Labelled ${ }^{13} \mathrm{CO}_{2}$ gas was used.

was higher for Silica_AEAPTS than for Silica_APTS, which was related to a higher loading of organics in Silica_AEAPTS.

Interestingly, signals in the ${ }^{13} \mathrm{C}$ MAS NMR spectra for the chemisorbed moieties of $\mathrm{CO}_{2}$ under wet conditions were much narrower than for those recorded under dry conditions, as can be seen by comparing the line widths for the respective ${ }^{13} \mathrm{C}$ NMR signals in Fig. 1. Our interpretation of the narrower distributions of ${ }^{13} \mathrm{C}$ NMR chemical shifts for the wet samples relates to the fact that the mobility of the chemisorbed $\mathrm{CO}_{2}$ as both carbamates and $\mathrm{HCO}_{3}{ }^{-}$was much higher under the wet conditions as compared to dry conditions. The co-adsorbed $\mathrm{H}_{2} \mathrm{O}$ appears to solvate the tethered amines and their chemisorbed $\mathrm{CO}_{2}$. 
For the $\mathrm{HCO}_{3}{ }^{-}$, we even expect that a large fraction was dissolved in the $\mathrm{H}_{2} \mathrm{O}$ adsorbed on the samples. Amine modified silica adsorbs $\mathrm{H}_{2} \mathrm{O}$ well already at low relative humidity, ${ }^{15,22}$ and we had subjected Silica_APTS, and Silica_AEAPTS to $100 \%$ relative humidity before the chemisorption of ${ }^{13} \mathrm{CO}_{2}$ for the wet samples. Under the dry conditions the spectroscopic dispersions of the carbamate moieties on Silica_APTS, and Silica_AEAPTS seem to have been larger and hence the corresponding ${ }^{13} \mathrm{C}$ NMR resonances were broader. It is important to mention that the relatively sharp signals, especially for the $\mathrm{HCO}_{3}{ }^{-}$species, has been scarcely seen, if ever, for these type of materials.

As mentioned, carbamate ammonium ion pairs formed on chemisorption of $\mathrm{CO}_{2}$ under both dry and wet conditions for Silica_APTS and Silica_AEAPTS, in addition to carbamic acid and $\mathrm{HCO}_{3}{ }^{-}$that formed in parallel under dry and wet conditions, respectively. $\mathrm{HCO}_{3}{ }^{-}$moieties are not expected to be observed under dry conditions since $\mathrm{H}_{2} \mathrm{O}$ plays a role in the $\mathrm{H}$-transfer that results in their formation, compare with Scheme 1(a).

Notably, in the Silica_AEAPTS wet sample, the ${ }^{13} \mathrm{C}$ NMR signal at $\sim 165 \mathrm{ppm}$ ascribed to the carbamate species were split in two, $c f$. Fig. 1 . This shoulder is thought to be due to the possibility of different moieties of carbamates being able to form in this case since the sample contains two amine groups, one being primary and the other being secondary ${ }^{14}$ (Scheme 1(b)).

Also in the ${ }^{1} \mathrm{H}$ NMR spectra, the NMR resonances were narrower for the wet samples than for the dry ones, as can be observed from the ${ }^{1} \mathrm{H}$ NMR signals in Fig. 2. This narrowing was ascribed to a more liquid-like character for the tethered amines and the chemisorbed $\mathrm{CO}_{2}$ in the wet samples. Co-adsorbed $\mathrm{H}_{2} \mathrm{O}$ has been shown to liberate the motion of the tethered and crosslinked molecules. ${ }^{47}$ It is also known that amine-modified silica materials have a higher hydrophilicity than bare silica leading to a situation where the conditions of the wet samples in this study were very close to those of liquid-filled pores, resulting in an enhancement of the mobility of the species. ${ }^{48}$

In the ${ }^{1} \mathrm{H}$ NMR region of $0.6-4$ ppm in Fig. 2, signals corresponding to the alkyl chains of the condensed moieties on the porous silica were observed. The ${ }^{1} \mathrm{H}$ NMR spectra were similar for the Silica_APTS and Silica_AEAPTS samples due to the similar chemical nature of the condensed or tethered amines, and the resolution, albeit high under wet conditions, did not make it possible to distinguish every ${ }^{1} \mathrm{H}$ NMR signal for each of the different $\mathrm{CH}_{2}$ groups in the Silica_AEAPTS sample. Nonetheless it was still possible to attribute the ${ }^{1} \mathrm{H}$ NMR resonaces at around $0.6 \mathrm{ppm}$ to the $-\mathrm{CH}_{2}$ - species directly bonded to silicon atoms. At around $1.5 \mathrm{ppm}$, the.signals for the $\beta-\mathrm{CH}_{2}-$ groups were observed, and at about 2.6-3.0 ppm the signals for the $\alpha-\mathrm{CH}_{2}-$ groups, next to the amine groups, were observed. For Silica_AEAPTS, the ${ }^{1} \mathrm{H}$ NMR signal for the $\alpha-\mathrm{CH}_{2}-$ was split in the spectrum for the wet sample. It is noted that the diamine (AEAPTS) had three $\alpha-\mathrm{CH}_{2}$ - group, two of which were connected to the secondary amine and one to the primary amine. Hence, the signal at $3.0 \mathrm{ppm}$ was tentatively assigned to the $\alpha-\mathrm{CH}_{2}-$ group of the primary amine. At $4.8-5.0 \mathrm{ppm}$, the ${ }^{1} \mathrm{H}$ NMR resonace for adsorbed $\mathrm{H}_{2} \mathrm{O}$ was observed for the Silica_APTS and Silica_AEAPTS samples, and the signal intensities were particularly intense for the wet samples. The -NHand $-\mathrm{NH}_{2}$ groups were, however, not detected directly in the ${ }^{1}$ H NMR spectra for Silica_APTS nor Silica_AEAPTS, likely due to chemical exchange with $\mathrm{H}_{2} \mathrm{O}$ or $\mathrm{Si}-\mathrm{OH}$ groups in both the dry and wet samples.

\section{2. $\mathrm{CO}_{2}$ adsorption measurements}

Adsorption isotherms of $\mathrm{CO}_{2}$ for pure and amine modified silica are shown in Fig. 3, all of them following the treatment with toluene for comparison. At low pressures (0-0.02 atm) of $\mathrm{CO}_{2}$, the amine modified sorbents showed a higher uptake of $\mathrm{CO}_{2}$ than the unmodified silica did, with the diaminated sample (Silica_AEAPTS) showing the highest level of $\mathrm{CO}_{2}$



Scheme 1 Scheme and structure of possible species formed during $\mathrm{CO}_{2}$ uptake of (a) the monoaminated Silica_APTS and (b) the diaminated Silica_AEAPTS. 


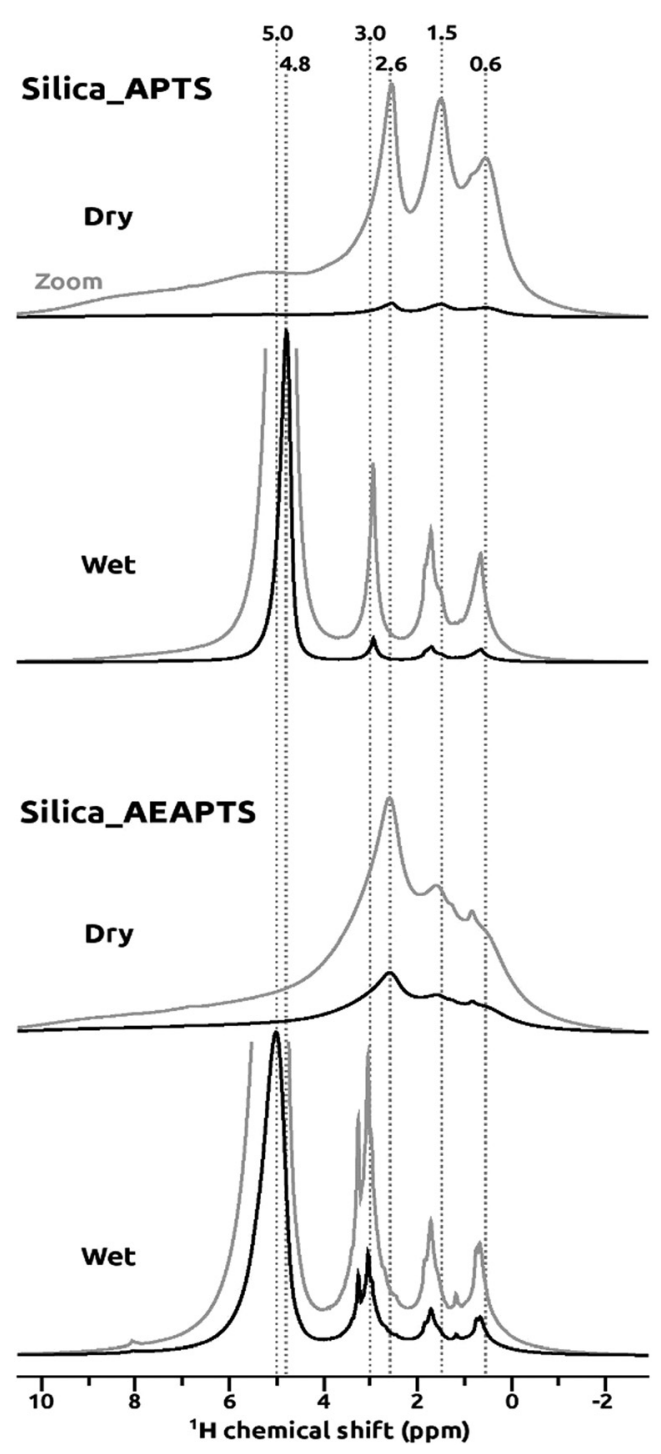

Fig. $2{ }^{1} \mathrm{H}$ NMR spectra in wet and dry conditions for samples modified with 3-aminopropyl)triethoxysilane (Silica_APTS) and 3-(2-aminoethylamino) propyltriethoxysilane (Silica_AEAPTS) after being subjected to $\mathrm{CO}_{2}$. The grey lines correspond to a zooming of the black ones and fast magic-angle spinning of $60.00 \mathrm{kHz}$ was used.

adsorption increase in this regime. For both amine modified silica samples, the $\mathrm{CO}_{2}$ isotherms had a much larger gradient at low pressures than for the unmodified silica as shown in Fig. 3 . The difference in gradients support established findings ${ }^{49,50}$ of a higher heat of chemisorption of $\mathrm{CO}_{2}$ on amine modified silica than for physisorption of $\mathrm{CO}_{2}$ on unmodified silica surfaces. On pure silica, $\mathrm{CO}_{2}$ adsorbs by physisorption, which is mainly governed by electrostatic interaction between $\mathrm{CO}_{2}$ and the silica surface.

The interaction is caused by the significant quadrupole moment of $\mathrm{CO}_{2}$ molecules and the electrical field variation of the silica surface. ${ }^{51}$ On amine-modified silica, $\mathrm{CO}_{2}$ chemisorbs, as discussed in sections above, and in the literature, ${ }^{14,15,25,27,46}$ as carbamate-ion pairs, carbamic acid or alike, or $\mathrm{HCO}_{3}{ }^{-}$ depending on the properties of the sorbent and conditions

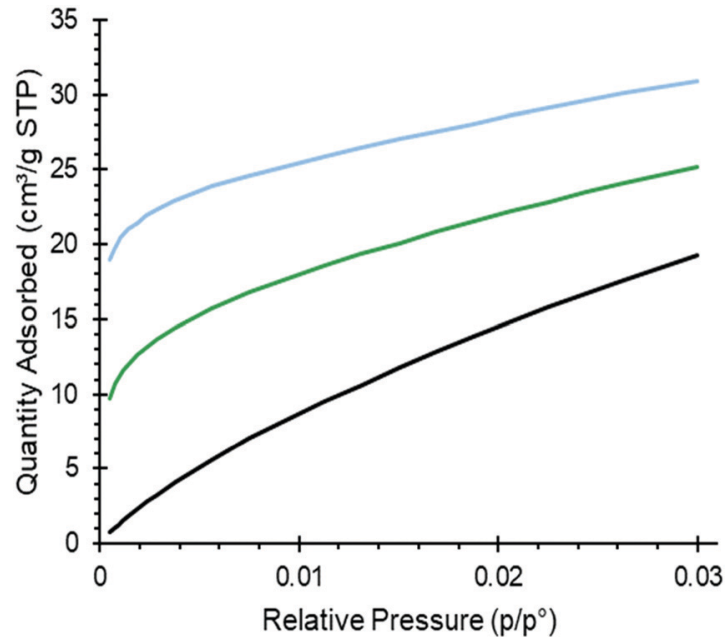

Fig. $3 \mathrm{CO}_{2}$ adsorption measurements at $0{ }^{\circ} \mathrm{C}$. Black: pure silica; green: Silica_APTS; blue: Silica_AEAPTS.

applied. A very high uptake of $\mathrm{CO}_{2}$ at a low pressure of $\mathrm{CO}_{2}$ for Silica_APTS shows a synergistic effect with carbamates forming across different propyl amine groups, which has been shown to occur above a critical amine density for monoamines. ${ }^{49,52,53}$ The very high $\mathrm{CO}_{2}$ uptake at a low pressure of $\mathrm{CO}_{2}$ for Silica_AEAPTS relates to intramolecular (and possibly intermolecular) carbamates being formed, which has been shown by e.g. Lashaki et al. ${ }^{54,55}$

\subsection{Thermogravimetric analysis}

The amount of organic groups in the Silica_APTS and Silica_AEAPTS were established with TGA by analyzing the mass loss recorded as the temperature increased within an appropriate temperature range. The temperature decomposition profiles can be seen in Fig. 4. From this, an estimation for the degree of modification of the amine-modified samples was extracted and

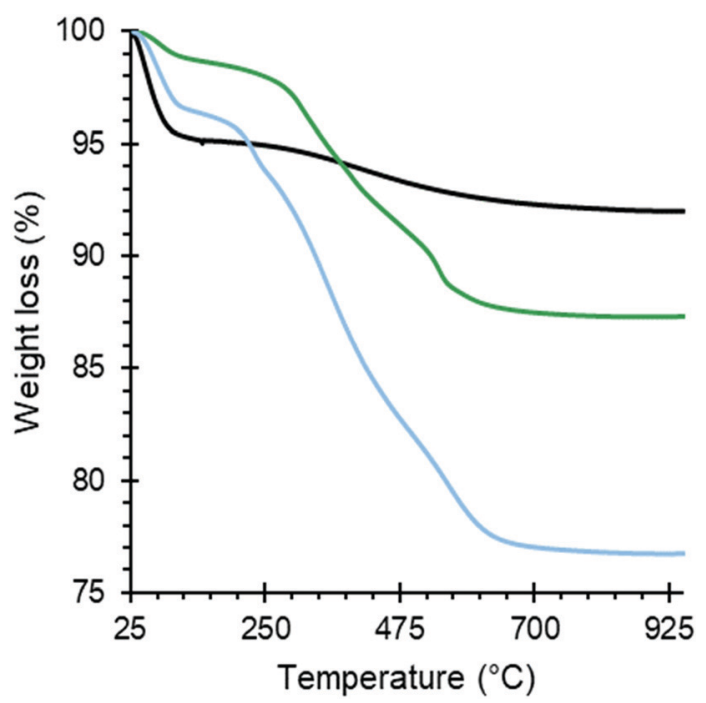

Fig. 4 TGA curves in dry air. Black: pure silica; green: Silica_APTS; blue: Silica_AEAPTS. 
Table 1 Degree of modification deduced from TGA

\begin{tabular}{llll}
\hline Sample & $\begin{array}{l}\text { Weight loss due } \\
\text { to organics (\%) }\end{array}$ & $\begin{array}{l}\text { Monomer } \\
\text { concentration }(\%)\end{array}$ & Monomer $/ \mathrm{SiO}_{2}$ \\
\hline Silica_APTS & 11 & 13.1 & 7.5 \\
Silica_AEAPTS & 21 & 16 & 6.5
\end{tabular}

presented in Table 1. It is also important to note that the diaminated Silica_AEAPTS presented an increased capacity to chemisorption of $\mathrm{CO}_{2}$ when compared to the monoaminated Silica_APTS, despite having a similar degree of modification molewise (Table 1), and simply ascribed to that each modification in the Silica_AEAPTS contained two reactive amine groups.

\section{Conclusions}

Here, mesoporous silica was modified with two different aminosilanes (the monoamine APTS and the diamine AEAPTS) and studied as $\mathrm{CO}_{2}$ sorbents. Systematic solid state NMR experiments were performed to study how $\mathrm{CO}_{2}$ chemisorbed under dry and moist conditions and the viability of using this technique under ultrahigh MAS conditions was tested. High quality spectra for both ${ }^{13} \mathrm{C}$ and ${ }^{1} \mathrm{H}$ NMR were detected especially in the case of the moist samples.

For both modified samples, $\mathrm{CO}_{2}$ chemisorbed as carbamic acid and carbamate ammonium ion pairs under dry conditions, and the directly-excited ${ }^{13} \mathrm{C}$ and $\left\{{ }^{1} \mathrm{H}\right\}{ }^{13} \mathrm{C}$ MAS NMR spectra obtained were significantly similar. When the samples were allowed to equilibrate in a humid environment (wet samples), carbamate ammonium ion pairs were again detected together with significant amounts of $\mathrm{HCO}_{3}{ }^{-}$instead of carbamic acids, by using either direct excitation ${ }^{13} \mathrm{C}$ or $\left\{{ }^{1} \mathrm{H}\right\}{ }^{13} \mathrm{C}$ NMR spectroscopy. The cross-polarization efficiency to the $\mathrm{HCO}_{3}{ }^{-}$was reduced as compared to the directly detected ${ }^{13} \mathrm{C}$ NMR. Still, with pre-knowledge of this tendency of reduction, $\left\{{ }^{1} \mathrm{H}\right\}^{13} \mathrm{C}$ NMR could be used to qualitatively establish the presence of $\mathrm{HCO}_{3}{ }^{-}$ for these samples without having to cool them down. We predict that $\left\{{ }^{1} \mathrm{H}\right\}{ }^{13} \mathrm{C}$ NMR can be used for qualitative assessment of $\mathrm{HCO}_{3}{ }^{-}$also without isotopic ${ }^{13} \mathrm{C}$ enrichment for similar samples, which would be convenient.

The presence of $\mathrm{H}_{2} \mathrm{O}$ in the aminated samples lead to a sharpening of all signals $\left({ }^{1} \mathrm{H}\right.$ and $\left.{ }^{13} \mathrm{C}\right)$ under rapid MAS, and the sharpening was ascribed to an enhanced mobility of the species. This sharpening allowed for detection of two different types of carbamates formed on chemisorption of $\mathrm{CO}_{2}$ on the diaminated sample as well as resolving most of the signals from the alkyl chains in the ${ }^{1} \mathrm{H}$ domain. These high resolutions of the ${ }^{1} \mathrm{H}$ and ${ }^{13} \mathrm{C}$ NMR spectra observed could open up for more understanding in the process of how amine-modified silicas capture $\mathrm{CO}_{2}$, can allow a better and more rational application of them, and sharpen their use in other important fields such as in catalysis.

\section{Conflicts of interest}

There are no conflicts to declare.

\section{Acknowledgements}

This project was supported by the EU-MSCA-ETN-GreenCarbon project 721991. The Swedish Research Council and the grant 2016-03568 is thanked for partial support of this study.

\section{References}

1 D. Aaron and C. Tsouris, Sep. Sci. Technol., 2005, 40, 321-348.

2 H. Yang, Z. Xu, M. Fan, R. Gupta, R. B. Slimane, A. E. Bland and I. Wright, J. Environ. Sci., 2008, 20, 14-27.

3 S. A. Didas, S. Choi, W. Chaikittisilp and C. W. Jones, Acc. Chem. Res., 2015, 48, 2680-2687.

4 E. Andreoli, E. P. Dillon, L. Cullum, L. B. Alemany and A. R. Barron, Sci. Rep., 2014, 4, 1-5.

5 J. F. Van Humbeck, T. M. McDonald, X. Jing, B. M. Wiers, G. Zhu and J. R. Long, J. Am. Chem. Soc., 2014, 136, 2432-2440.

6 X. Shi, H. Xiao, H. Azarabadi, J. Song, X. Wu, X. Chen and K. S. Lackner, Angew. Chem., Int. Ed., 2020, 59, 6984-7006.

7 G. Zhao, B. Aziz and N. Hedin, Appl. Energy, 2010, 87, 2907-2913.

8 A. Goeppert, S. Meth, G. K. S. Prakash and G. A. Olah, Energy Environ. Sci., 2010, 3, 1949-1960.

9 R. W. Flaig, T. M. O. Popp, A. M. Fracaroli, E. A. Kapustin, M. J. Kalmutzki, R. M. Altamimi, F. Fathieh, J. A. Reimer and O. M. Yaghi, J. Am. Chem. Soc., 2017, 139, 39.

10 F. Y. Chang, K. J. Chao, H. H. Cheng and C. S. Tan, Sep. Purif. Technol., 2009, 70, 87-95.

11 N. Hedin and Z. Bacsik, Curr. Opin. Green Sustainable Chem., 2019, 16, 13-19.

12 S. Zhang, C. Chen and W. S. Ahn, Curr. Opin. Green Sustainable Chem., 2019, 16, 26-32.

13 Y. Zhai, H. Jin and S. S. C. Chuang, Chemistry of Silica and Zeolite-Based Materials, Elsevier, 2019, pp. 121-142.

14 J. K. Moore, M. A. Sakwa-Novak, W. Chaikittisilp, A. K. Mehta, M. S. Conradi, C. W. Jones and S. E. Hayes, Environ. Sci. Technol., 2015, 49, 13684-13691.

15 Z. Bacsik, N. Ahlsten, A. Ziadi, G. Zhao, A. E. Garcia-Bennett, B. Martín-Matute and N. Hedin, Langmuir, 2011, 27, 11118-11128.

16 S.-J. Huang, C.-T. Hung, A. Zheng, J.-S. Lin, C.-F. Yang, Y.-C. Chang, F. Deng and S.-B. Liu, J. Phys. Chem. Lett., 2014, 5, 3.

17 G. S. Foo, J. J. Lee, C.-H. Chen, S. E. Hayes, C. Sievers and C. W. Jones, ChemSusChem, 2017, 10, 266-276.

18 A. Danon, P. C. Stair and E. Weitz, J. Phys. Chem. C, 2011, 115, 11540-11549.

19 C. Knöfel, C. Martin, V. Hornebecq and P. L. Llewellyn, J. Phys. Chem. C, 2009, 113, 21726-21734.

20 N. Hiyoshi, K. Yogo and T. Yashima, Microporous Mesoporous Mater., 2005, 84, 357-365.

21 D. J. Fauth, M. L. Gray, H. W. Pennline, H. M. Krutka, S. Sjöström and A. M. Ault, Energy Fuels, 2012, 26, 2483-2496. 
22 Y. Belmabkhout, R. Serna-Guerrero and A. Sayari, Chem. Eng. Sci., 2010, 65, 3695-3698.

23 S. A. Didas, M. A. Sakwa-Novak, G. S. Foo, C. Sievers and C. W. Jones, J. Phys. Chem. Lett., 2014, 5, 4194-4200.

24 V. Zelenak, D. Halamova, L. Gaberova, E. Bloch and P. Llewellyn, Microporous Mesoporous Mater., 2008, 116, 358-364.

25 A. C. C. Chang, S. S. C. Chuang, M. Gray and Y. Soong, Energy Fuels, 2003, 17, 468-473.

26 C.-H. Yu, C.-H. Huang and C.-S. Tan, Aerosol Air Qual. Res., 2012, 12, 745-769.

27 C. H. Chen, D. Shimon, J. J. Lee, F. Mentink-Vigier, I. Hung, C. Sievers, C. W. Jones and S. E. Hayes, J. Am. Chem. Soc., 2018, 140, 8648-8651.

28 M. W. Hahn, M. Steib, A. Jentys and J. A. Lercher, J. Phys. Chem. C, 2015, 119, 4126-4135.

29 X. Wang, V. Schwartz, J. C. Clark, X. Ma, S. H. Overbury, X. Xu and C. Song, J. Phys. Chem. C, 2009, 113, 7260-7268.

30 G. Richner and G. Puxty, Ind. Eng. Chem. Res., 2012, 51, 14317-14324.

31 R. Zhang, Z. Liang, H. Liu, W. Rongwong, X. Luo, R. Idem and Q. Yang, Ind. Eng. Chem. Res., 2016, 55, 3710-3717.

32 X. Yang, R. J. Rees, W. Conway, G. Puxty, Q. Yang and D. A. Winkler, Chem. Rev., 2017, 117, 9524-9593.

33 D. Bernin and N. Hedin, Curr. Opin. Colloid Interface Sci., 2018, 33, 53-62.

34 C.-H. Chen, D. Shimon, J. J. Lee, S. A. Didas, A. K. Mehta, C. Sievers, C. W. Jones and S. E. Hayes, Environ. Sci. Technol., 2017, 51, 26.

35 P. Rzepka, Z. Bacsik, A. J. Pell, N. Hedin and A. Jaworski, J. Phys. Chem. C, 2019, 123, 21497-21503.

36 F. Mani, M. Peruzzini and P. Stoppioni, Green Chem., 2006, 8, 995-1000.

37 R. W. Flaig, T. M. Osborn Popp, A. M. Fracaroli, E. A. Kapustin, M. J. Kalmutzki, R. M. Altamimi, F. Fathieh, J. A. Reimer and O. M. Yaghi, J. Am. Chem. Soc., 2017, 139, 12125-12128.

38 B. Aziz, G. Zhao and N. Hedin, Langmuir, 2011, 27, 3822-3834.
39 T. L. Hwang, P. C. M. Van Zijl and M. Garwood, J. Magn. Reson., 1998, 133, 200-203.

40 G. Kervern, G. Pintacuda and L. Emsley, Chem. Phys. Lett., 2007, 435, 157-162.

41 B. M. Fung, A. K. Khitrin and K. Ermolaev, J. Magn. Reson., 2000, 142, 97-101.

42 T. Čendak, L. Sequeira, M. Sardo, A. Valente, M. L. Pinto and L. Mafra, Chem. - Eur. J., 2018, 24, 10136-10145.

43 C. Te Hung, C. F. Yang, J. S. Lin, S. J. Huang, Y. C. Chang and S. Bin Liu, Microporous Mesoporous Mater., 2017, 238, 2-13.

44 M. L. Pinto, L. Mafra, J. M. Guil, J. Pires and J. Rocha, Chem. Mater., 2011, 23, 1387-1395.

45 L. Mafra, T. Čendak, S. Schneider, P. V. Wiper, J. Pires, J. R. B. Gomes and M. L. Pinto, J. Am. Chem. Soc., 2017, 139, 389-408.

46 P. V. Kortunov, M. Siskin, L. S. Baugh and D. C. Calabro, Energy Fuels, 2015, 29, 5919-5939.

47 L. Phillips, F. Separovic, B. A. Cornell, J. A. Barden and C. G. dos Remedios, Eur. Biophys. J., 1991, 19, 147-155.

48 F. Rezaei, R. P. Lively, Y. Labreche, G. Chen, Y. Fan, W. J. Koros and C. W. Jones, ACS Appl. Mater. Interfaces, 2013, 5, 3921-3931.

49 Z. Bacsik, R. Atluri, A. E. Garcia-Bennett and N. Hedin, Langmuir, 2010, 26, 10013-10024.

50 M. W. Hahn, J. Jelic, E. Berger, K. Reuter, A. Jentys and J. A. Lercher, J. Phys. Chem. B, 2016, 120, 1988-1995.

51 R. Roque-Malherbe, R. Polanco-Estrella and F. MarquezLinares, J. Phys. Chem. C, 2010, 114, 17773-17787.

52 P. D. Young and J. M. Notestein, ChemSusChem, 2011, 4, 1671-1678.

53 B. Aziz, N. Hedin and Z. Bacsik, Microporous Mesoporous Mater., 2012, 159, 42-49.

54 M. Jahandar Lashaki, S. Khiavi and A. Sayari, Chem. Soc. Rev., 2019, 48, 3320-3405.

55 M. A. Alkhabbaz, P. Bollini, G. S. Foo, C. Sievers and C. W. Jones, J. Am. Chem. Soc., 2014, 136, 13170-13173. 